and 27.8 per cent, respectively, in the previous year. Non-recurrent grants in respect of capital expenditure totalled $£ 9,134,185$, compared with $£ 7,084,366$ in 1955-56, and of the recurrent expenditure of $£ 41,509,703$-an increase of $9 \cdot 1$ per cent on $1955-56$ -7.0 per cent was spent on administration, 68.4 per cent on departmental maintenance, and 12.9 per cent on maintenance of premises. The largest increases were in rates, insurance, heat, light, water, wages, etc. (15.3 per cent), departmental wages (technicians and laboratory assistants) (14 per cent), and in repairs and maintenance of buildings (13.9 per cent). Expenditure on libraries (excluding general maintenance, rates, etc.) increased from $£ 1,468,512$ to $£ 1,620,958$ but remained at 3.9 per cent of the total.

\title{
SCIENTIFIC FILMS AT THE BRITISH ASSOCIATION
}

$\mathrm{F}^{\mathrm{o}}$ OR the fourth successive year the Scientific and Technical Group of the Royal Photographic Society of Great Britain, in conjunction with the Scientific Films Committee of the British Association, presented a series of research films as part of the annual meeting of the British Association. These films were shown in two sessions during the morning and afternoon of August 30. The morning session was under the chairmanship of Sir Raymond Priestley, and during the afternoon $\mathrm{Mr}$. Bowler, vice-president of the Society, took the chair.

Several films were devoted to biological subjects, from the study of the mating behaviour of marsupial frogs to the investigation of cancerous cells. The muscle structure of sea-anemones, courtship of Drosophila melanogaster, nematodes and Leishmania donovani were also objects of investigation. In what might be described as the industrial field many problems have been covered with ciné techniques, including the casting of steel, coke-oven performance, vehicle suspension systems, flooring research, bookbinding operations and the flow of water in large pipes.

From the psychological aspect, two films were shown which demonstrated techniques that have been employed to identify the particular point of a general scene at which a subject is looking, thus enabling eye co-ordination to be studied. Also in this field an extract was shown from a film which studied parent/child relationship in an experimental treatment of the problems involved in admission to hospital of children under school age.

In pure physics, the motion of electrons in electric fields was demonstrated by means of charged droplets ; this film was made in Germany. Automatic self-replication was also shown by ingenious systems of models. Finally, Mr. Hallett, secretary of the Society, gave a short talk on the scope and aims of the "Encyclopædia Cinematographica", with examples of research films loaned by Dr. Wolf, of Göttingen.

Among the methods used to prepare these films were time-lapse and high-speed ciné-photography, interference and phase-contrast microscopy, electron microscopy and television techniques. Colour and monochrome, silent and sound-track films were all represented at this meeting, which admirably demonstrated the wide variety of ways in which photography can be of use in research in an equally wide range of scientific investigation.

A more detailed report will be published in the Journal of Photographic Science.

\section{A STRUCTURAL THEORY FOR METAL ALKOXIDE POLYMERS}

\author{
By DR. D. C. BRADLEY
}

Department of Chemistry, Birkbeck College, University of London

$\mathrm{R}$ ECEN'T studies ${ }^{1,2}$ on the metal alkoxides $M(\mathrm{O} R)_{n}$, where $M$ is an $n$-valent metal and $R$ is an alkyl group, have established that derivatives with the lower primary or secondary alkyl groups are in fact polymeric, that is $\left\{M(\mathrm{O} R)_{n}\right\}_{x}$, where $x$ is the degree of polymerization. It is believed that this polymerization is caused by intermolecular bonds involving the metal and oxygen atoms, namely :

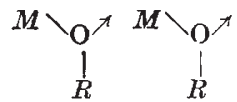

and is a manifestation of the tendency of the metal to expand its covalency by co-ordination with oxygen. It is a striking feature of the metal alkoxides that the alternative mechanism for this covalency expansion, namely, co-ordination between the alkoxide and a ligand containing oxygen or nitrogen (for example, $\left.M(\mathrm{O} R)_{n}, x L\right)$ is relatively rare and this suggests a special stability for the polymer. Moreover, it is a general rule that, in a series of metal alkoxides with metals of the same sub-group (for example, titanium, zirconium, thorium) and having the same alkyl groups, the degree of polymerization $x$ increases with the size of the metal atom. Nevertheless, only in a few cases have structures been suggested for metal alkoxide polymers ${ }^{3-7}$. Another interesting feature of these compounds is that the polymers are relatively small compared with typical organic polymers and silicones. Recent studies on the hydrolysis of titanium alkoxides ${ }^{8,9}$ showed that the titanium oxide alkoxides $\mathrm{TiO}_{h}(\mathrm{O} R), h$ formed were also low polymers, and this behaviour was explained in terms of a series of structural models in which titanium was 6 -co-ordinated by oxygen. Further consideration of these structures reveals that in each case the degree of polymerization is unique in being the lowest possible, and this led me to explore the possibility of rationalizing the polymeric nature of metal alkoxides in terms of the stereochemistry of the metal. It is the purpose of this article to show that a rationalization can indeed be achieved on the basis of the following single new major assumption. It is assumed that the metal alkoxide adopts the smallest possible structural unit consistent with all the metal atoms attaining a higher co-ordination number. Also the choice of structure is limited by the condition that the co-ordination number of oxygen does not exceed 